\title{
Predictive factors and practice trends in red blood cell transfusions for very-low-birth-weight infants
}

\author{
Osayame A. Ekhaguere', Frank H. Morriss Jr², Edward F. Bell ${ }^{2}$, Nadkarni Prakash ${ }^{3}$ and John A. Widness ${ }^{2}$
}

BACKGROUND: Red blood cell (RBC) transfusions in verylow-birth-weight (VLBW) infants, while common, carry risk. Our objective was to determine clinical predictors of and trends in RBC transfusions among VLBW infants.

METHODS: RBC transfusion practice and its clinical predictors in 1,750 VLBW $(\leq 1,500 \mathrm{~g})$ infants were analyzed in a singlecenter cohort across sequential epochs: 2000-2004 (Epoch 1), 2005-2009 (Epoch 2), and 2010-2013 (Epoch 3).

RESULTS: Overall, 1,168 (67\%) infants received $\geq 1$ transfusions. The adjusted likelihood of $\geq 1$ transfusions decreased for each $1-\mathrm{g} / \mathrm{dl}$ increment in initial hemoglobin concentration following birth, for females, and for each 100-g increment in birth weight. The adjusted likelihood of $\geq 1$ transfusions increased with infants receiving mechanical ventilation, with increasing length of hospital stay, necrotizing enterocolitis, and nonlethal congenital anomalies requiring surgery. The adjusted mean (SEM) number of transfusions per patient was decreased in Epoch 3, compared with Epoch 1 and Epoch 2. For an initial hemoglobin of $\geq 16.5 \mathrm{~g} / \mathrm{dl}$, the predicted probability of being transfused was $\leq 50 \%$.

CONCLUSION: Adjusted RBC transfusions declined and female sex conferred an unexplained protection over the study period. Modest increases in initial hemoglobin by placentofetal transfusion at delivery may reduce the need for RBC transfusion.

$\mathbf{R}^{\mathbf{c}}$ ed blood cell (RBC) transfusion is the most common therapy for the treatment of anemia in very-low-birth-weight (VLBW) infants. An estimated 70\% of VLBW infants receive at least one transfusion within the first 4 wk of life (1), with $~ 80 \%$ receiving $\geq 1 \mathrm{RBC}$ transfusions during their hospital stay (2). RBC transfusions, although lifesaving, can lead to immediate and delayed adverse transfusion reaction (3) and have been associated with intraventricular hemorrhage (4), necrotizing enterocolitis (NEC) (5), retinopathy of prematurity (6), and bronchopulmonary dysplasia (7).

The practice of administering $\mathrm{RBC}$ transfusions is largely governed by the degree of prematurity and severity of illness of the infant. Few studies have examined the clinical characteristics of VLBW infants that require RBC transfusions (8-10). These studies have either been in subsets of infants weighing less than $1,000 \mathrm{~g}$ or of small sample size. As the survival rate among VLBW infants continues to improve and clinicians become more cognizant of the risks associated with RBC transfusions, it is important to reexamine the clinical predictors and trends of RBC transfusions. We hypothesized that doing so would identify important, potentially modifiable factors that would enable reducing exposure to RBC transfusions among VLBW infants.

\section{RESULTS}

Of the 1,825 VLBW infants who met inclusion criteria, 35 were excluded from the analysis because they had been enrolled in a research trial in which RBC transfusion criteria was prescribed (11). Seven infants were excluded because they had received an exchange blood transfusion, and 33 were excluded due to incomplete data (i.e., discrepant number of RBC transfusions, incomplete documentation of number of days on mechanical ventilation). Characteristics of the 1,750 VLBW infants available for analyses changed over epochs (Table 1). Birth weight (BW), gestational age (GA), length of stay and the incidence of NEC increased over time. During the study period, $66.7 \%$ of infants received $\geq 1 \mathrm{RBC}$ transfusions (Table 2). There was no difference across epochs in the unadjusted number of RBC transfusions administered per infant.

To assess independent clinical predictors of $\geq 1$ RBC transfusions, multivariable logistic regression analysis (Table 3 ) revealed that the likelihood of receiving $\geq 1 \mathrm{RBC}$ transfusions decreased with each $1.0 \mathrm{~g} / \mathrm{dl}$ increment of initial hemoglobin concentration ( $\mathrm{Hgb})$ after birth (aOR 0.70, CI 0.65-0.75), female sex (aOR 0.64, CI 0.47-0.87), and with 100-g BW increments (aOR 0.71, CI 0.65-0.76). The clinical factors that independently increased the likelihood of any transfusion included nonlethal congenital anomaly requiring surgery (aOR 6.97, CI 1.57-30.89), time spent mechanically ventilated, $(1-7 \mathrm{~d}$ [aOR 1.79, CI 1.25-2.57], 7-28 d [aOR 8.33, CI 4.78-14.51], and $\geq 28 \mathrm{~d}$ [aOR $67.41 \mathrm{CI} 8.79-517.00$ ]), and each incremental

'Department of Neonatology, Children's Hospital of Philadelphia, Philadelphia, Pennsylvania; ${ }^{2}$ Stead Family Department of Pediatrics, Roy J. and Lucille A. Carver College of Medicine and University of lowa Children's Hospital, University of lowa, lowa City, lowa; ${ }^{3}$ Department of Internal Medicine, Roy J. and Lucille A. Carver College of Medicine and University of lowa Children's Hospital, University of lowa, lowa City, lowa. Correspondence: Osayame A. Ekhaguere (ekhaguereo@email.chop.edu)

Received 23 August 2015; accepted 28 October 2015; advance online publication 3 February 2016. doi:10.1038/pr.2016.4 
Table 1. Study population clinical characteristics by epoch

\begin{tabular}{|c|c|c|c|c|c|}
\hline Characteristic & All epochs & $\begin{array}{c}\text { Epoch } 1 \\
(2000-2004, N=562)\end{array}$ & $\begin{array}{c}\text { Epoch } 2 \\
(2005-2009, N=685)\end{array}$ & $\begin{array}{c}\text { Epoch } 3 \\
(2010-2013, N=503)\end{array}$ & $P^{a}$ \\
\hline Female, $N(\%)$ & $873(49.9)$ & $279(49.6)$ & $334(48.8)$ & $260(51.7)$ & 0.52 \\
\hline Birth weight, g, mean (SD) & $1026(294)$ & $1001(292)$ & $1042(297)$ & $1033(290)$ & 0.04 \\
\hline$\leq 500, \mathrm{~g}, N(\%)$ & $61(3.5)$ & $21(3.7)$ & $24(3.5)$ & $16(3.2)$ & \\
\hline $501-750, \mathrm{~g}, N(\%)$ & $299(17.1)$ & $104(18.2)$ & $111(16.2)$ & $84(16.7)$ & \\
\hline $751-1,000, g, N(\%)$ & $441(25.2)$ & $154(26.9)$ & $161(23.5)$ & $126(25.1)$ & $0.008^{b}$ \\
\hline $1,251-1,500 \mathrm{~g}, \mathrm{~N}(\%)$ & $506(28.9)$ & $136(23.8)$ & $215(31.4)$ & $155(30.8)$ & \\
\hline Gestational age, weeks, mean (SD) & $28.0(2.8)$ & $27.8(2.8)$ & $28.1(2.7)$ & $28(2.9)$ & 0.04 \\
\hline$<26 w k, N(\%)$ & $355(20.3)$ & $136(24.2)$ & $121(17.7)$ & $98(19.5)$ & \\
\hline $26-28 w k, N(\%)$ & $648(37.0)$ & $210(37.4)$ & $263(38.4)$ & $175(34.8)$ & \\
\hline $29-30 \mathrm{wk}, N(\%)$ & $435(24.9)$ & $124(22.1)$ & $179(26.1)$ & $132(26.2)$ & $0.004^{b}$ \\
\hline Appropriate for gestational age, $N(\%)$ & $1366(78.06)$ & 449 (79.9) & $530(77.4)$ & $387(76.9)$ & $0.44^{b}$ \\
\hline Large for gestational age, $N(\%)$ & $11(0.63)$ & $3(0.53)$ & $3(0.44)$ & $5(1.0)$ & \\
\hline \multicolumn{6}{|l|}{ Mechanical ventilation days (\%) } \\
\hline None, $N(\%)$ & $420(24.0)$ & $147(26.2)$ & $159(23.2)$ & $114(22.7)$ & \\
\hline $1-7, N(\%)$ & $549(31.4)$ & $141(25.1)$ & $255(37.2)$ & $153(30.4)$ & \\
\hline $8-27, N(\%)$ & $308(17.6)$ & $121(21.5)$ & $104(15.2)$ & $83(16.5)$ & $0.43^{b}$ \\
\hline$\geq 28, N(\%)$ & $473(27.0)$ & $153(27.2)$ & $167(24.4)$ & $153(30.4)$ & \\
\hline \multicolumn{6}{|l|}{ Intraventricular hemorrhage } \\
\hline None, $N(\%)$ & $1444(82.5)$ & $452(80.4)$ & $570(83.2)$ & $422(83.9)$ & \\
\hline Duration of any respiratory support, median (IQR) & $12(1-38)$ & $13(1-37)$ & $11(1-37)$ & $12(1-44)$ & 0.85 \\
\hline Duration of supplemental $\mathrm{O}_{2^{\prime}}$, days, median (IQR) & $42(11-84)$ & $46(9-89)$ & $40(11-78)$ & $43(13-88)$ & 0.29 \\
\hline Length of hospital stay, days, median (IQR) & $63(41-90)$ & $64(36-91)$ & $61(41-85)$ & $65(45-94)$ & 0.03 \\
\hline Hemoglobin, g/dL mean (SD) & $15.8(2.7)$ & $15.9(2.7)$ & $15.9(2.8)$ & $15.6(2.6)$ & 0.09 \\
\hline Died in NICU, N (\%) & $87(5.0)$ & $34(6.1)$ & $33(4.8)$ & $20(4.0)$ & 0.12 \\
\hline
\end{tabular}

$\mathrm{NICU}$, neonatal intensive care unit.

a $P$ values across epochs. ${ }^{b} P$ value across subcategories.

hospital day (aOR 1.04, CI 1.03-1.05). Every infant who developed NEC received at least one RBC transfusion. Inclusion of the nursery neurobiologic risk score (NBRS) as an additional predictor or a replacement for assisted ventilation duration in the multivariable logistic regression model did not improve the model fit; therefore, time spent on mechanical ventilation was utilized as a proxy for illness severity throughout the entire hospital stay.

In assessing RBC transfusion trends, compared with Epoch 3 , the likelihood of receiving $\geq 1 \mathrm{RBC}$ transfusions was greater in Epoch 1 (aOR 2.39, CI 1.56-3.65) and Epoch 2 (aOR 2.81, CI 1.90-4.15). The adjusted mean (SEM) number of RBC transfusions per subject derived from the Poisson regression analysis was 2.05 (0.12) in Epoch 3, compared with 2.40 (0.14) in Epoch 1 and 2.58 (0.15) in Epoch 2.

The adjusted probability of receiving $\geq 1$ transfusions for any initial Hgb decreased in Epoch 3 compared to Epoch 1 and Epoch 2 is shown in Figure 1. The figure is an effect plot for the subgroup of males who were not ventilated, did not develop NEC and did not have surgery for congenital anomaly; the continuous variables of BW per $100 \mathrm{~g}$ and length of stay in days were held at their midpoints in the model. The predicted probability of receiving $\geq 1 \mathrm{RBC}$ transfusions, as estimated by the effect probability plot, in the most recent epoch was $50 \%$ for an 


\section{Articles | Ekhaguere et al.}

Table 2. Univariate analysis of RBC transfusions in VLBW infants by epoch

\begin{tabular}{|c|c|c|c|c|c|}
\hline & All & $\begin{array}{c}\text { Epoch } 1 \\
(2000-2004, N=562)\end{array}$ & $\begin{array}{c}\text { Epoch } 2 \\
(2005-2009, N=685)\end{array}$ & $\begin{array}{c}\text { Epoch } 3 \\
(2010-2013, N=503)\end{array}$ & $P^{a}$ \\
\hline Number per patient, median (IQR) & $2(0-5)$ & $2(0-5)$ & $2(0-5)$ & $2(0-5)$ & 0.18 \\
\hline None, $N(\%)$ & $582(33.3)$ & $178(31.7)$ & $218(31.8)$ & $186(37.0)$ & \\
\hline $1, N(\%)$ & $228(13.0)$ & $62(11.0)$ & $110(16.1)$ & $56(11.1)$ & \\
\hline $6-10, N(\%)$ & $271(15.5)$ & $96(17.1)$ & $98(14.3)$ & $77(15.3)$ & \\
\hline $11-15, N(\%)$ & $71(4.1)$ & $25(4.5)$ & $29(4.2)$ & $17(3.4)$ & \\
\hline$>15, N(\%)$ & $25(1.4)$ & $9(1.6)$ & $10(1.5)$ & $6(1.2)$ & \\
\hline
\end{tabular}

ap value across epochs. ${ }^{b} P$ value across subcategories.

Table 3. Multivariable logistic regression analysis for the predictors of the outcome any RBC transfusion

\begin{tabular}{lc}
\hline Predictor & Odds ratio $(95 \% \mathrm{Cl})$ \\
\hline Epoch & \\
Epoch 1 vs. Epoch 3 & $2.39(1.56-3.65)$ \\
Epoch 2 vs. Epoch 3 & $2.81(1.90-4.15)$ \\
Epoch 3 & Reference \\
Female sex & $0.64(0.47-0.87)$ \\
Birth weight (per 100 g increment) & $0.71(0.65-0.76)$ \\
Ventilator duration, days & \\
None & Reference \\
$1-7$ d vs. none & $1.79(1.25-2.57)$ \\
$8-27$ d vs. none & $8.33(4.78-14.51)$ \\
$\geq 28$ d vs. none & $67.41(8.79-517.00)$ \\
Nonlethal congenital anomalies requiring surgery & $6.97(1.57-30.89)$ \\
Length of stay (per day increment) & $1.04(1.03-1.05)$ \\
Initial Hgb at birth (per g/dL increment) & $0.7(0.65-0.75)$ \\
(AGA or LGA) vs. SGA & $1.37(0.89-2.13)$ \\
\hline
\end{tabular}

Model includes necrotizing enterocolitis; all patients who had NEC were transfused, yielding an adjusted OR of infinity.

C statistic is 0.942 .

SGA, small for gestational age; AGA, appropriate for gestational age; LGA, large for gestational age; RBC, red blood cell; NEC, necrotizing enterocolitis; OR, odds ratio.

initial $\mathrm{Hgb}$ of $\sim 16.5 \mathrm{~g} / \mathrm{dl}$ and was less than $50 \%$ for higher initial Hgb values. In epoch 3, for any initial Hgb, the probability of requiring $\geq 1 \mathrm{RBC}$ transfusions is less in females compared to males (Figure 2).

\section{DISCUSSION}

Of the examined clinical predictors of RBC transfusions in VLBW infants in this single-center retrospective study, initial $\mathrm{Hgb}$ following delivery was found to have a major effect on the likelihood of administering $\geq 1$ RBC transfusions. Each $1 \mathrm{~g} / \mathrm{dl}$ increment in initial Hgb decreased the adjusted likelihood of receiving $\geq 1 \mathrm{RBC}$ transfusions by $30 \%$. For an $\mathrm{Hgb}$ of $\sim 16.5 \mathrm{~g} / \mathrm{dl}$, the predicted probability of being transfused was $50 \%$, and this probability declined as the initial Hgb

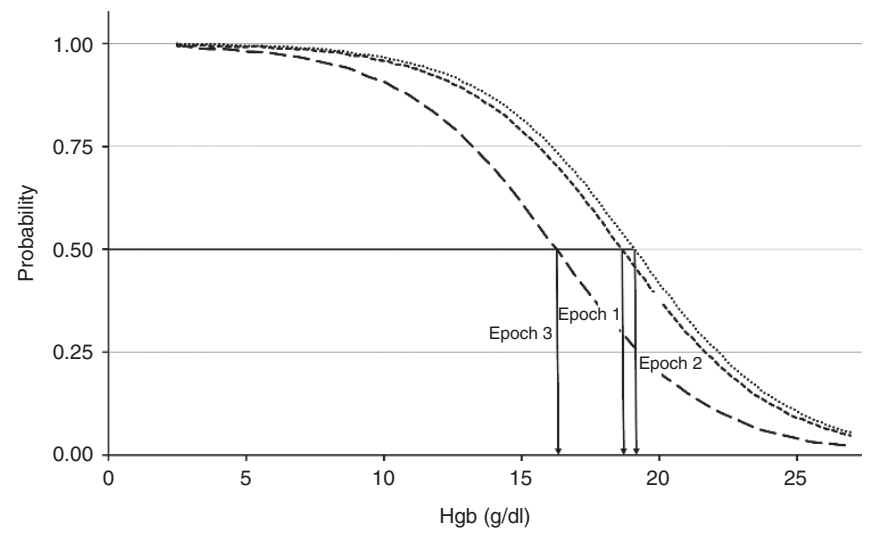

Figure 1. Probability of male infants being transfused based on initial hemoglobin concentration during 3 epochs. For any level of $\mathrm{Hgb}$, the probability of $\geq 1 \mathrm{RBC}$ transfusions is less in epoch 3, thick dashed curve, compared to epoch 1 , light dotted curve and epoch 2 thick dotted curve. The arrows indicate the $\mathrm{Hgb}$ level which predict $50 \%$ probability of $\geq 1 \mathrm{RBC}$ transfusion. Effect probability plot are for males who were not ventilated, did not develop NEC or have surgery for congenital anomaly. Continuous variables held at their midpoints included in the model are birthweight per $100 \mathrm{~g}$ and length of stay in days. $\mathrm{Hgb}$, initial hemoglobin concentration following birth; RBC, red blood cell; NEC, necrotizing enterocolitis.

increased. These findings suggest that modest increments in initial Hgb achieved by placentofetal transfusion at birth might yield clinically meaningful reductions in the need for RBC transfusions.

Of the other clinical predictors, several have been reported previously and thus were expected. Also, given that ventilator support is included in our institutional RBC transfusion guideline, we expected it to be predictive. However, female sex was an unexpected independent predictor that decreased the adjusted likelihood of $\geq 1 \mathrm{RBC}$ transfusions. Female sex was also associated with a reduced Hgb concentration that predicted a 50\% likelihood of requiring an RBC transfusion when compared to males.

Three prior observational studies have reported a similar relationship between higher initial Hgb and reduced administration of RBC transfusions to preterm infants. However, two examined only extremely-low-birth-weight infants, the majority of whom received concurrent erythropoietin therapy, thus 


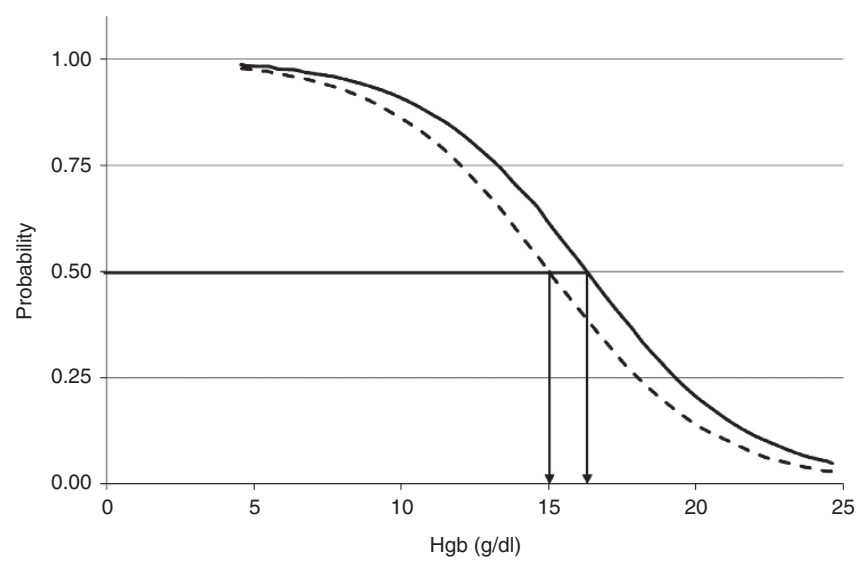

Figure 2. Probability of male and female infants being transfused based on initial hemoglobin concentration during Epoch 3. For any level of $\mathrm{Hgb}$, the probability of $\geq 1 \mathrm{RBC}$ transfusion is less in females, dotted curve, compared to males, dashed curve, in epoch 3 . The arrows indicate the $\mathrm{Hgb}$ level which predict $50 \%$ probability of $\geq 1 \mathrm{RBC}$ transfusion. Effect probability plot are for males and females infants were not ventilated, did not develop NEC or have surgery for congenital anomaly. Continuous variables held at their midpoints included in the model are birthweight per $100 \mathrm{~g}$ and length of stay in days. Hgb, initial hemoglobin concentration following birth; RBC, red blood cell; NEC, necrotizing enterocolitis.

confounding direct comparison with this study $(8,9)$. The third study reported only $P$ values without effect size (10).

Randomized clinical trials on placentofetal transfusion in preterm infants have reported larger blood volumes (12), higher Hgb concentration after birth (13-15), and fewer overall RBC transfusions in infants exposed to delayed cord clamping or umbilical cord milking (16-18). In addition, improved neurodevelopmental status at $7 \mathrm{mo}$ (19) and 4 y (20) have been reported in some longitudinal studies of term infants. A Cochrane review examining delayed cord clamping or cord milking vs. immediate cord clamping found fewer transfusions of packed RBCs, better circulatory stability, less intraventricular hemorrhage (all grades), decreased oxygen requirement at 36 wk corrected GA and lower risk for NEC with delayed cord clamping or cord milking (21).

However, disruption of timely resuscitation, the ideal duration of time to delay cord clamping, and whether umbilical cord milking is a safe and effective alternative to delayed cord clamping $(22,23)$ remain concerns requiring further study. Also, there continues to be a need for clinical data on the longterm neurodevelopmental implications of these strategies in preterm infants $(23,24)$.

To our knowledge, this is the first report to identify female sex as an independent protective factor for requiring $\mathrm{RBC}$ transfusions. In the reviewed literature, there does not appear to be any direct relationship between male sex and decreased red cell mass, erythropoietin production, impaired bone marrow function or increased RBC senescence. However, it has been suggested that when compared to females, males carry an unexplained intrinsic risk for adverse neonatal outcomes overall (25). Males have higher rates of neonatal mortality, respiratory morbidities, and adverse neurologic outcomes, even after adjusting for maternal factors, GA and BW (26).
The other observed factors in this study that contributed to the likelihood of RBC transfusions relate to the degree of prematurity and the severity of illness. Nonlethal congenital anomalies requiring surgery, time spent on mechanical ventilation, NEC and per day increments of length of hospital stay were all significantly associated with an increased likelihood of requiring $\geq 1 \mathrm{RBC}$ transfusions. These factors are difficult to modify given current neonatal intensive care unit (NICU) therapies. Together and individually, they reflect the severity of illness of the infant. As such, they commonly necessitate frequent blood sampling for close clinical monitoring. It is common for the cumulative phlebotomy loss for laboratory analysis during the first weeks of life to equal or exceed the infant's total circulating blood volume (27); estimates of laboratory phlebotomy loss among preterm infants vary from 1.1 to $3.5 \mathrm{ml} / \mathrm{kg} / \mathrm{d}$ in the first few weeks of life (28-30). Techniques for reducing phlebotomy losses, such as utilizing placental blood at birth for initial laboratory analyses (31) and inline analyzers/point-of care blood test analyzers have been shown to reduce phlebotomy losses in the first week of life by $25 \%$ and to reduce the exposure to RBC transfusion by $33-48 \%$ without any adverse short- or long-term outcomes $(27,32)$.

The secondary aim of this study was to evaluate the temporal trend in RBC transfusions in VLBW infants over the 14-y study period. Figure 1 depicts this trend clearly. Each curve represents the probability of being transfused by epoch based on the initial Hgb after birth. At any level of starting hemoglobin, the probability of being transfused was decreased in epoch 3 when compared to epoch 1 and 2 . The adjusted likelihood of exposure to $\geq 1$ RBC transfusions and the adjusted mean number of RBC transfusions both decreased in the most recent epoch compared with earlier epochs. This occurred despite the lack of change in institutional RBC transfusion guidelines.

From the same NICU, we previously reported a significant decrease in the unadjusted number of transfusions per infant compared at three different years: 1982, 1989, and 1993 (1). The percent of VLBW infants transfused during hospitalization in 1982 and 1993 were 88 and 62\%, respectively. The unadjusted number of transfusions (mean \pm SD) per infant was $7.0 \pm 7.4$ in 1982 and $2.3 \pm 2.7$ in 1993 . However, major changes occurred over the study period that influenced transfusion practice. These included the identification of human immunodeficiency virus, improved practice of administering maternal corticosteroids, administration of pulmonary surfactant to infants with respiratory distress syndrome, and adoption of stricter RBC transfusion criteria. In the current study timeframe, a comparable proportion of VLBW infants, $66.7 \%$, received one or more RBC transfusions. There was no difference across epochs in the unadjusted number of RBC transfusions per infant, but the adjusted mean number of transfusions decreased.

We speculate that the reduced adjusted mean number of transfusions in the most recent epoch may be due to clinicians being more conservative in prescribing transfusions. They may not be following the transfusion guideline strictly but using clinical judgment to decide. In addition, and of minor effect, is the influence of the research trial in which RBC transfusion 
criteria was prescribed (11), in which our institution became a part of in 2013. Infants not enrolled in the trial may be placed at a transfusion threshold closer to the restrictive threshold, thus reducing overall transfusions. However, compliance with institutional transfusion guideline was not available; therefore, we cannot ascertain if less stringent adherence to institutional transfusion guideline accounts for the reduced transfusion numbers in the most recent epoch.

It is important to recognize other strengths and weaknesses of the current study. Although the study includes a large and robust dataset, allowing for adjustment for many predictors of transfusion, we are limited by its observational nature. Thus, we may not have identified and studied all predictors. In addition, it is a single-center study, limiting its generalizability to other centers.

\section{Conclusions}

In conclusion, a small decrease in the adjusted likelihood of being transfused was observed from 2000 to 2013, but $63 \%$ of VLBW required at least one RBC transfusion in the most recent epoch. Strategies aimed at optimizing $\mathrm{Hgb}$ at birth through placentofetal transfusion and limiting phlebotomy losses have the potential to reduce further the number of RBC transfusions VLBW infants receive.

\section{METHODS}

We performed a cohort analysis of VLBW infants admitted to the NICU at the University of Iowa Children's Hospital from 2000 to 2013. Data were obtained from a prospectively collected NICU registry, a database of clinical information on patients admitted to the NICU. The NICU registry data were supplemented and validated by electronic medical chart review. We included all infants with BW $\leq 1500 \mathrm{~g}$ who were admitted within $72 \mathrm{~h}$ of birth and survived longer than $48 \mathrm{~h}$. Infants were excluded if they had an exchange blood transfusion, had incomplete data or were subjects in a research trial in which RBC transfusion criteria were prescribed (11).

The study was approved by the University of Iowa Institutional Review Board. A waiver of parental consent was obtained as the study posed minimal risk. Also, it was impractical to consent each subject given the study period.

\section{RBC Transfusion Procedures and Guidelines}

Throughout the entire study period, the NICU RBC transfusion guidelines developed in 1998 remained unchanged (33). Infants were transfused with $15 \mathrm{ml} / \mathrm{kg}$ of packed RBC (hematocrit $80-85 \%$ ) when: (i) Hgb was $<13 \mathrm{~g} / \mathrm{dl}$ and the infant was mechanically ventilated with $\mathrm{FiO}_{2} \geq 0.7$, had sepsis or NEC; (ii) $\mathrm{Hgb}$ was $<11.5 \mathrm{~g} / \mathrm{dl}$ and the infant was mechanically ventilated with $\mathrm{FiO}_{2} \leq 0.7$ or receiving nasopharyngeal continuous positive airway pressure with $\mathrm{FiO}_{2} \geq 0.4$; (iii) $\mathrm{Hgb}$ was $<10 \mathrm{~g} / \mathrm{dl}$, receiving nasopharyngeal continuous positive airway pressure with $\mathrm{FiO}_{2} \leq 0.4$ or before a surgical procedure; (iv) $\mathrm{Hgb}$ was $<8 \mathrm{~g}$ / dl without supplemental oxygen, but with clinical signs of anemia; or (v) Hgb was $<7 \mathrm{~g} / \mathrm{dl}$ without supplemental oxygen or clinical signs of anemia.

During the study period delayed cord transfusion was not implemented. This practice was instituted in 2014.

\section{Study Definitions}

To assess the effect of time on transfusion practice, the cohort was grouped into three sequential epochs: 2000-2004 (Epoch 1), 2005-2009 (Epoch 2), and 2010-2013 (Epoch 3). Clinical predictors examined included BW, GA, appropriateness of BW for GA, sex, length of stay until discharge, transfer or death, initial Hgb recorded after birth, presence of nonlethal congenital anomalies requiring surgery (i.e., intestinal atresia, esophageal atresia, surgically corrected patent ductus arteriosus), time receiving supplemental oxygen, time receiving mechanical ventilation, intraventricular hemorrhage severity (34), and NEC by the modified Bell classification stage IIA or higher (35). Severity of illness throughout hospitalization was estimated with the nursery neurobiologic risk score system (36). The nursery neurobiologic risk score incorporates subcategories of seven parameters: infection, blood $\mathrm{pH}$, seizures, intraventricular hemorrhage, assisted ventilation, periventricular leukomalacia, and hypoglycemia.

\section{Statistical Analyses}

To characterize and compare patient groups across epochs, means, medians, and variances of continuous variables and distributions of categorical variables were calculated and tested using analysis of variance, $\chi^{2}$, and Kruskal-Wallis tests. Cochrane-Mantel-Haenszel and Cochrane-Armitage tests were used to assess RBC transfusion trends across epochs. Multivariable logistic regression analysis was performed to identify independent clinical predictors for the outcome of $\geq 1$ transfusions. A Poisson regression analysis for the outcome of adjusted mean number of transfusions by epoch was also performed. Adjusted effect plots of transfusion probability as a function of initial Hgb were calculated for each epoch. Statistical analyses were performed with SAS 9.4 (SAS Institute Inc. Cary, NC).

\section{ACKNOWLEDGMENTS}

The authors acknowledge Gretchen Cress BSN, RN, MPH of the Division of Neonatology, University of lowa Children's Hospital, for her assistance in the data extraction and IRB application. Also, the authors thank Mark Hart of the Division of Neonatology, University of lowa Children's Hospital, and Denison Kuruvilla of the College of Pharmacy, University of lowa, for their contributions to the editing the manuscript and figures.

\section{STATEMENT OF FINANCIAL SUPPORT}

This research was supported by US Public Health Service (USPHS) grant P01 HL046925 and The National Center for Research Resources, a part of the National Institutes of Health (NIH), Grant Number UL1RR024979, University of lowa, lowa City, lowa.

Disclosure: None of the authors have conflicts of interest, including financial interests, activities, relationships, or affiliations to disclose.

\section{REFERENCES}

1. Widness JA, Seward VJ, Kromer IJ, Burmeister LF, Bell EF, Strauss RG. Changing patterns of red blood cell transfusion in very low birth weight infants. J Pediatr 1996;129:680-7.

2. Strauss RG, Levy GJ, Sotelo-Avila C, et al. National survey of neonatal transfusion practices: II. Blood component therapy. Pediatrics 1993;91:530-6.

3. Galel SA, Fontaine MJ. Hazards of neonatal blood transfusion. NeoReviews 2006;7:e69-75.

4. Christensen RD, Baer VL, Lambert DK, Ilstrup SJ, Eggert LD, Henry E. Association, among very-low-birthweight neonates, between red blood cell transfusions in the week after birth and severe intraventricular hemorrhage. Transfusion 2014;54:104-8.

5. Mally P, Golombek SG, Mishra R, et al. Association of necrotizing enterocolitis with elective packed red blood cell transfusions in stable, growing, premature neonates. Am J Perinatol 2006;23:451-8.

6. Dani C, Martelli E, Bertini G, et al. Effect of blood transfusions on oxidative stress in preterm infants. Arch Dis Child Fetal Neonatal Ed 2004;89: F408-11.

7. Vamvakas EC, Blajchman MA. Transfusion-related immunomodulation (TRIM): an update. Blood Rev 2007;21:327-48.

8. Hosono S, Mugishima H, Kitamura T, et al. Effect of hemoglobin on transfusion and neonatal adaptation in extremely low-birthweight infants. Pediatr Int 2008;50:306-11.

9. Hosono S, Mugishima H, Shimada M, et al. Prediction of transfusions in extremely low-birthweight infants in the erythropoietin era. Pediatr Int 2006;48:572-6.

10. Paul DA, Pearlman SA, Leef KH, Stefano JL. Predicting red blood cell transfusions in very low birth weight infants based on clinical risk factors. Del Med J 1997;69:555-61. 
11. Eunice Kennedy Shriver National Institute of Child Health and Human Development (NICHD): Transfusion of Prematures Trial (TOP). https:// clinicaltrials.gov/show/NCT01702805. Accessed 23 December 2015.

12. Aladangady N, McHugh S, Aitchison TC, Wardrop CA, Holland BM. Infants' blood volume in a controlled trial of placental transfusion at preterm delivery. Pediatrics 2006;117:93-8.

13. Oh W, Fanaroff AA, Carlo WA, Donovan EF, McDonald SA, Poole WK; Eunice Kennedy Shriver National Institute of Child Health and Human Development Neonatal Research Network. Effects of delayed cord clamping in very-low-birth-weight infants. J Perinatol 2011;31:Suppl 1: S68-71.

14. Strauss RG, Mock DM, Johnson KJ, et al. A randomized clinical trial comparing immediate versus delayed clamping of the umbilical cord in preterm infants: short-term clinical and laboratory endpoints. Transfusion 2008;48:658-65.

15. Kugelman A, Borenstein-Levin L, Riskin A, et al. Immediate versus delayed umbilical cord clamping in premature neonates born $<35$ weeks: a prospective, randomized, controlled study. Am J Perinatol 2007;24:307-15.

16. Rabe H, Diaz-Rossello JL, Duley L, Dowswell T. Effect of timing of umbilical cord clamping and other strategies to influence placental transfusion at preterm birth on maternal and infant outcomes. Cochrane Database Syst Rev 2012;8:CD003248.

17. Hosono S, Mugishima H, Fujita $\mathrm{H}$, et al. Umbilical cord milking reduces the need for red cell transfusions and improves neonatal adaptation in infants born at less than 29 weeks' gestation: a randomised controlled trial. Arch Dis Child Fetal Neonatal Ed 2008;93:F14-9.

18. Kinmond S, Aitchison TC, Holland BM, Jones JG, Turner TL, Wardrop CA. Umbilical cord clamping and preterm infants: a randomised trial. BMJ 1993;306:172-5.

19. Mercer JS, Vohr BR, Erickson-Owens DA, Padbury JF, Oh W. Sevenmonth developmental outcomes of very low birth weight infants enrolled in a randomized controlled trial of delayed versus immediate cord clamping. J Perinatol 2010;30:11-6.

20. Andersson O, Lindquist B, Lindgren M, Stjernqvist K, Domellöf M, Hellström-Westas L. Effect of delayed cord clamping on neurodevelopment at 4 years of age: a randomized clinical trial. JAMA Pediatr 2015;169:631-8.

21. Al-Wassia H, Shah PS. Efficacy and safety of umbilical cord milking at birth: a systematic review and meta-analysis. JAMA Pediatr 2015;169: $18-25$.

22. Bell EF. Transfusion thresholds for preterm infants: how low should we go? J Pediatr 2006;149:287-9.
23. Whyte R, Kirpalani H. Low versus high haemoglobin concentration threshold for blood transfusion for preventing morbidity and mortality in very low birth weight infants. Cochrane Database Syst Rev 2011;11:Cd000512.

24. Bell EF. Increasing the placental transfusion for preterm infants. Obstet Gynecol 2011;117:203-4.

25. Peacock JL, Marston L, Marlow N, Calvert SA, Greenough A. Neonatal and infant outcome in boys and girls born very prematurely. Pediatr Res 2012;71:305-10.

26. Stevenson DK, Verter J, Fanaroff AA, et al. Sex differences in outcomes of very low birthweight infants: the newborn male disadvantage. Arch Dis Child Fetal Neonatal Ed 2000;83:F182-5.

27. Widness JA, Madan A, Grindeanu LA, Zimmerman MB, Wong DK, Stevenson DK. Reduction in red blood cell transfusions among preterm infants: results of a randomized trial with an in-line blood gas and chemistry monitor. Pediatrics 2005;115:1299-306.

28. Widness JA. Treatment and prevention of neonatal anemia. Neoreviews 2008;9:526-33.

29. Obladen M, Sachsenweger M, Stahnke M. Blood sampling in very low birth weight infants receiving different levels of intensive care. Eur J Pediatr 1988;147:399-404.

30. Rosebraugh MR, Widness JA, Nalbant D, Veng-Pedersen P. A mathematical modeling approach to quantify the role of phlebotomy losses and need for transfusions in neonatal anemia. Transfusion 2013;53:1353-60.

31. Carroll PD, Nankervis CA, Iams J, Kelleher K. Umbilical cord blood as a replacement source for admission complete blood count in premature infants. J Perinatol 2012;32:97-102.

32. Mahieu L, Marien A, De Dooy J, Mahieu M, Mahieu H, Van Hoof V. Implementation of a multi-parameter Point-of-Care-blood test analyzer reduces central laboratory testing and need for blood transfusions in very low birth weight infants. Clin Chim Acta 2012;413:325-30.

33. UI NICU Guidelines for Erythrocyte Transfusions to Neonates. http:// www.uichildrens.org/childrens-content.aspx?id=234059. Accessed 23 December 2015.

34. Papile LA, Burstein J, Burstein R, Koffler H. Incidence and evolution of subependymal and intraventricular hemorrhage: a study of infants with birth weights less than 1,500 gm. J Pediatr 1978;92:529-34.

35. Bell MJ, Ternberg JL, Feigin RD, et al. Neonatal necrotizing enterocolitis. Therapeutic decisions based upon clinical staging. Ann Surg 1978;187:1-7.

36. Brazy JE, Eckerman CO, Oehler JM, Goldstein RF, O'Rand AM. Nursery Neurobiologic Risk Score: important factor in predicting outcome in very low birth weight infants. J Pediatr 1991;118:783-92. 